Hideo Nagashima MD, Hung D. Nguyen MD, Michael Conforti MD, Deryck Duncalf MD, Paul L. Goldiner MD, Francis F. Foldes MD

\title{
A simple method for monitoring muscular relaxation during continuous infusion of vecuronium
}

There is considerable individual variation in the dose of vecuronium required for the maintenance of surgical relaxation. Therefore to provide uninderrupted relaxation without overdosage it is advisable to regulate the $W$ infusion of vecuronium on the basis of appropriate monitoring. Monitoring with mechanomyography (MMG) or electromyography requires costly equipment and is too complex for routine clinica! use. Visual abservation of the adductor pollicis muscte contracting against zero resistance is not suitable for the reliable assessment of the degree of neuramuscular (NM) block. For clinical purposes satisfactory monitoring can be achieved with the simple device (Myoscan) described. The reliability of the Myoscan was tested in 30 patients by simultaneows monitoring of the force of contraction of the adductor palicis on one side with the Myoscan and on the contralateral side with the MMG. Retrospective analysis of the MMG indicated that the conduct of anaesthesia would have been virtually the same if it would have been based on MMG monitoring.

\section{Key words}

MEASUREMENT TECHNIQUES: neuTOMUSCular blockade, Myoscan; NEUROMUSCULAR RELAXANTS: vecuronium.

From the Department of Anesthesiology, Montefiore Medical Center and Albert Einstein College of Medicine, Bronx, New York.

Address correspondence to: Dr. F.F. Foldes, Monteīiore Medical Center, 111 East 210th Street, Bronx, NY 10467.

Supported by a grant from Organon Inc., West Orange, New Jersey.
Because of the intermediate duration of its action it is convenient to administer vecuronium bromide by continuous IV infusion for maintenance of muscular relaxation during relatively long surgical procedures. There is a wide individual variation in vecuronium requirements ${ }^{1-10}$ (Table l). Therefore, to achieve uninterrupted relaxation with continuous infusion of a muscle relaxant (MR), without the use of unnecessarily large doses, neuromuscular (NM) blockade should be continuously monitored. Monitoring can be accomplished by recording the mechanomyogram (MMG), electromyogram (EMG) or by visual observation of the response of the adductor pollicis or some other suitable muscle, to indirect stimulation by single impulses administered at $0.1 \mathrm{~Hz}$ or by $2 \mathrm{sec}$ trains of $2 \mathrm{~Hz}$ impulses (TOF stimulation). ${ }^{11}$ Recording of the MMG or EMG requires expensive equipment and is too complex for routine clinical use. Visual observation of a muscle contracting against zero resistance does not allow reliable assessment of the degree of NM block. For clinical purposes satisfactory monitoring can be achieved by a simple, inexpensive device called the "Myoscan" (Figure). To demonstrate this the muscular relaxation achieved with the continuous IV infusion of vecuronium was monitored simultaneously with the Myoscan on one and the MMG on the other upper extremity in 30 patients.

\section{Methods}

This study was approved by the Institutional Review Board of Montefiore Medical Center and all ASA physical status Class I and II patients participating gave informed consents. Of the 30 patients, eight were males and 22 were females. Their mean age was $45.8 \pm 2.8(26$ to 65$)$ years; mean weight was $72.2 \pm 1.5(60.5$ to 92.9$) \mathrm{kg}$. Patients were premedicated with 50 to $100 \mathrm{mg}$ IM diphenhydramine and meperidine each. Anaesthesia was induced with $0.001 \mathrm{mg} \cdot \mathrm{kg}^{-\mathrm{l}}$ fentanyl, $0.10 \mathrm{mg} \cdot \mathrm{kg}^{-1}$ droperidol, a "sleep dose" ( $2 \mathrm{to} 3 \mathrm{mg} \mathrm{kg}^{-1}$ ) of thiopentone and $\mathrm{N}_{2} \mathrm{O} 4 \mathrm{~L} \cdot \mathrm{min}^{-1}-\mathrm{O}_{2} 2 \mathrm{~L} \cdot \mathrm{min}^{-1}$. Anaesthesia was maintained with increments of fentanyl plus the above $\mathrm{N}_{2} \mathrm{O}-\mathrm{O}_{2}$ mixture. After induction of anaesthesia 200 to 
$300 \mathrm{~g}$ resting tension was applied to the adductor pollicis muscles and the ulnar nerves at the wrist were stimulated (Constant Current Nerve Stimulator, Model FR, Rusz Instruments, Inc.), through surface electrodes, with TOF supramaximal, square wave impulses of $0.2 \mathrm{~ms}$ duration, administered every $10 \mathrm{~s}$. On one side the force of contraction of the adductor pollicis muscle was quantitated by FTIO transducers and continuously recorded on a Grass polygraph. On the contralateral side the contractions of the adductor pollicis muscle were observed visually on the Myoscan.

It has been observed (Nagashima $H$ and Foldes FF, unpublished observations) that after administration of vecuronium or other nondepolaring $M R$, when the force of contraction elicited with single supramaximal, $0.1 \mathrm{~Hz}$ impulses decreased to 15 to 25 per cent of control only $T_{1}$ of TOF impulses elicited a definite response on the contralateral side on the Myoscan. Furthermore, when in the course of recovery of NM transmission the force of contraction increased to about 15,25 or 35 per cent of control, $T_{2}, T_{3}$ and $T_{4}$ respectively elicited visible responses on the Myoscan. On the basis of this information the trachea was intubated when, after administration of a single $0.1 \mathrm{mg} \mathrm{kg}^{-1}$ IV dose of vecuronium, the first of TOF impulses $\left(T_{1}\right)$ elicited a response on the Myoscan. When the second TOF stimulus $\left(T_{2}\right)$ again elicited a visible response, the IV infusion of $0.04 \mathrm{mg} \cdot \mathrm{ml}^{-1}$ vecuronium solution (10 mg vecuronium dissolved in $250 \mathrm{ml} 0.9$ per cent $\mathrm{NaCl}$ ) was started at the rate of $2 \mathrm{ml} \cdot$ min $^{-1}$ (80 $\mu \mathrm{g} \cdot \mathrm{min}^{-1}$ ). Subsequently, the rate of infusion was so adjusted that only $T_{1}$ elicited visible expansion of the spring of the Myoscan.

When there was no further clinical need for muscular relaxation, the vecuronium infusion was discontinued and spontaneous recovery of the force of contraction of the adductur pollicis was recorded with the MMG on one side for as long as conditions (e.g., need to vacate the operating room) allowed. On the contralateral side the times at which $T_{2}, T_{3}$ and $T_{4}$ first elicited a response on the Myoscan were noted. If at the time when the patient had to be removed from the operating room the responses elicited on the Myoscan by $T_{1}, T_{2}, T_{3}$ and $T_{4}$ appeared to be uneven the residual NM block was reversed. This was accomplished with a mixture of $0.08 \mathrm{mg} \cdot \mathrm{min}^{-1}$ atropine and $0.1 \mathrm{mg} \cdot \mathrm{min}^{-1}$ pyridostigmine. The force of contraction of the adductor pollicis elicited by TOF stimuli was recorded at 2,5 and 8 min after the end of injection of the antagonist on one side and observed on the Myoscan on the contralateral side. Recovery was considered to be clinically satisfactory when the responses clicited by $T_{1}$, $T_{2}, T_{3}$ and $T_{4}$ appeared to be equal and similar to those observed before administration of vecuronium. If at $8 \mathrm{~min}$ the responses to the TOF stimuli appeared to be unequal

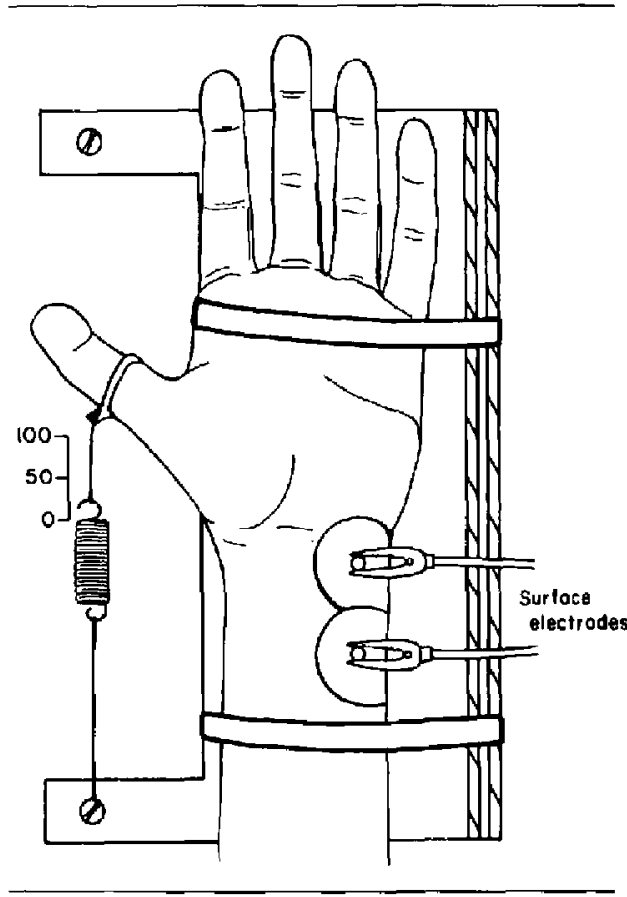

FIGURE The Myoscan consists of an armboard with an appropriate cutout, a metal of plastic ring, and a spring with about 400 to 600 $\mathrm{g} \cdot \mathrm{cm}^{-1}$ compliance. The upper extremity used for the IV infusion is attached to the armboard in either the supine or prone position. Surface electrodes are placed above the ulnar nerve at the wrist and the ring is attached to the second pholanx of the thumb. The ring is connected with a short thread to the proximal end of the spring. After induction of anaesthesia sufficicnt pull is exerted on a second thread to the distal end of the spring to make the thumb perpendicular to the hand and to apply 200 to $400 \mathrm{~g}$ resting tension to it. This tension is maintained by winding the distal end of the second thread around a metal screw driven into the armboard and sccuring it with a piece of adhesive tape. The ulnar nerve is stimulated by trains-of -4 (TOF) supramaximal, square wave impulses of 0.2 Jns duration, administered al $2 \mathrm{~Hz}$, every $10 \mathrm{~s}$. See "Methods" for evaluation of the status of muscular relaxation and the regulation of the use of muscle relaxants and anticholinesterases with the help of the Myoscan.

andior smaller than those observed before the administration of vecuronium, the recovery was observed for an additional $4 \mathrm{~min}$. If at that time recovery was still incomplete $0.05 \mathrm{mg}^{\mathrm{kg}} \mathrm{k}^{-1}$ pyridostigmine was administered and, depending on the heart rate 0.003 to 0.006 $\mathrm{mg} \cdot \mathrm{kg}^{-1}$ atropine was also injected.

\section{Results}

The MMG indicated that maximal NM block produced by the $0.1 \mathrm{mg}^{-1} \mathrm{~kg}^{-1}$ intubating dose of vecuronium was $98.5 \pm$ 
TABLE I Vecuronium requirements for maintenance of mascular relaxalion by continuous intravenous infusion

\begin{tabular}{|c|c|c|c|c|}
\hline \multirow[b]{2}{*}{ Aufhors } & \multirow{2}{*}{$\begin{array}{l}\text { Numbur of } \\
\text { patients }\end{array}$} & \multicolumn{2}{|c|}{ Dose $\left(\mu g \cdot \mathrm{kg}^{-i} \min \cdot^{-1}\right)$} & \multirow[b]{2}{*}{ Anaesshesia } \\
\hline & & Mean $\pm S E M$ & Range & \\
\hline $\begin{array}{l}\text { Agoston et al.' } \\
\text { d'Hollander et al. }{ }^{2 *}\end{array}$ & 9 & $0.91 \pm 0.16$ & $0.18-1.42$ & Balanced \\
\hline Age (years) $<40$ & 8 & $1.13 \pm 0.18$ & - & Balanced \\
\hline $40-60$ & 8 & $1.09 \pm 0.13$ & 一 & Balanced \\
\hline$>60$ & 8 & $0.72 \pm 0.09$ & - & Balanced \\
\hline d'Hollander $e t a l .^{3 *}$ & 20 & $0.55 \pm 0.09$ & $0.10-1.12$ & Balanced \\
\hline Noeldge et $a l^{4}$ & 12 & 1.25 & 一 & Balanced \\
\hline Mirakhur el al. ${ }^{3}$ & 10 & $1.38 \pm 0.11$ & - & Balanced \\
\hline d'Hollander $e t$ al. ${ }^{6}$ & 15 & $1.13 \pm 0.1 \mathrm{l}$ & - & Balanced \\
\hline \multirow[t]{2}{*}{ Swen et al. ${ }^{7}$} & 6 & $1.25 \pm 0.11$ & - & Balanced \\
\hline & 6 & $0.79 \pm 0.07$ & - & Halothane \\
\hline$\emptyset_{\text {stergaard }}{ }^{B}$ & 15 & 1.67 & - & Balanced \\
\hline de Vries et al." & 28 & 1.10 & $0.80-1.50$ & Balanced \\
\hline Hyman ef al. $\uparrow$ & 30 & $1.17 \pm 0.10$ & $0.48-2.50$ & Balanced \\
\hline \multirow[t]{3}{*}{ Cannon et al. ${ }^{10}$} & 5 & $1.04 \pm 0.22$ & $0.50-1.75$ & Balanced \\
\hline & 6 & $0.34 \pm 0.06$ & $0.10-0.50$ & Enflurane \\
\hline & 6 & $0.26 \pm 0.04$ & $0.10-0.40$ & Isoflurane \\
\hline
\end{tabular}

*In the studies of d'Hollander et al, ${ }^{3,5,6}$ the vecuronium tequirements at equilibrium were expressed in $\mu \mathrm{g} \cdot \mathrm{m}^{-2} 10 \mathrm{~min}^{-1}$. These values were converted to $\mu \mathrm{g} \cdot \mathrm{kg}^{-1} \cdot \mathrm{min}^{-1}$ assuming that the body sturface area of an average $70 \mathrm{ke}$ subject is $1.7 \mathrm{~m}^{2}$.

tScientific Exhibit at the 1986 A nnual Meeting of the ASA, Las Vegas, Nevada, October 17-2t.

0.4 per cent and that it developed in $2.8 \pm 0.2 \mathrm{~min}$. Based on the observation of the Myoscan the maximal effect (no visible response to stimulation) also developed in $2.8 \pm 0.2 \mathrm{~min}$. Intubation time based on the observation of the Myoscan was 2.0 $\pm 0.1 \mathrm{~min}$. If patients would have been intubared when $T_{1}$ on the MMG indicated 80 per cent NM block the intubation time would have been $1.6 \pm 0.1 \mathrm{~min}$. The clinical duration of the $0.1 \mathrm{mg} \cdot \mathrm{kg}^{-1}$ vecuronium assessed from the observation of the Myoscan ( $T_{1}$ elicited a distinct, $T_{2}$ a barely visible response) was $41.3 \pm 2.0 \mathrm{~min}$. At this time the MMG indicated that the force of contraction of the adductor pollicus retumed to $15.3 \pm 1.2$ per cent of control. Muscular relaxation was satisfactory when only $T_{1}$ of TOF stimuli elicited a response. The mean $( \pm S E M)$ duration of infusion was $76.2 \pm 14.0(12.0$ to 352.0$) \mathrm{min}$ and its rate was $0.90 \pm$ $0.05(0.38$ to 1.50$) \mu \mathrm{g} \cdot \mathrm{kg}^{-1} \cdot \mathrm{min}^{-1}$.

After discontinuation of the infusion MMG indicated that the force of contraction recovered spontaneously to 25 per cent of control in $11.9 \pm 1.4 \min (n=25)$ and the recovery rate (from 25 per cent to 75 per cent of control) was $14.7 \pm 2.0(n=7)$. The residual NM block could be reversed by $0.1 \mathrm{mg} \cdot \mathrm{kg}^{-1}$ pyridostigmine. The recovery of NM transmission, as indicted by the $T_{4} / T_{1}$ ratios on the MMG, was more complete and developed more quickly when the $T_{4} / T_{1}$ ratio before the administration of the antagonist was $>0.2$ (Table $\mathrm{I}$ ).
No cardiovascular or other side effects, attributable to vecuronium, were observed in either group.

\section{Discussion}

The findings of this study indicate that after the administration of an $0.1 \mathrm{mg} \cdot \mathrm{kg}^{-1}$ initial dose, satisfactory muscular relaxation can be maintained by the continuous IV infusion of about $0.9 \mu \mathrm{g} \cdot \mathrm{kg}^{-1} \cdot \mathrm{min}^{-1}$ vecuronium. To achieve rapidly the 85 to 95 per cent steady state NM block of the adductor pollicis necessary for surgical relaxation the infusion of vecuronium should be started as soon as the NM effect of its initial dose starts to wear off. In agreement with the findings of other investigators ${ }^{1-10}$ there

TABLE II The relationship belween the $T_{4} / T_{1}$ ratio before reversal and the effect of pyridostigmine

\begin{tabular}{llll}
\hline & \multicolumn{3}{l}{$\begin{array}{l}T_{\phi} / T_{i} \text { ratio } \\
\text { Min after administration of antagonist* }\end{array}$} \\
\cline { 2 - 4 } $\begin{array}{l}\text { Before } \\
\text { reversal }\end{array}$ & 2 & 5 & 8 \\
\hline$<0.2(12)$ & $0.31 \pm 0.05 \dagger$ & $0.53 \pm 0.05$ & $0.65 \pm 0.06$ \\
$>0.2(15)$ & $0.62 \pm 0.05$ & $0.76 \pm 0.05$ & $0.82 \pm 0.02$ \\
\hline
\end{tabular}

*0.1 mg $\cdot \mathrm{kg}^{-1}$ pyridestigmine and $0.008 \mathrm{mg} \cdot \mathrm{kg}^{-1}$ atropinc.

tAll values are means \pm SEM of number of observations indicared in parenthesis. 
TABLE III Simultaneous monitoring of the concinuous infusion of vecuronium with myoscan and MMG

\begin{tabular}{|c|c|c|c|}
\hline \multirow[b]{2}{*}{ Time of observation } & \multirow[b]{2}{*}{ Observations made with the Myascan } & \multicolumn{2}{|c|}{ Data recorded on the $M M G$} \\
\hline & & $\begin{array}{l}T_{1} \\
\text { (\% of Control) }\end{array}$ & $\begin{array}{l}T_{4} / T_{I} \\
\text { Ratio }\end{array}$ \\
\hline Before vecuronium & Equal response to 4 stimuli & 100.0 & $0.9 \pm 0.01$ \\
\hline Before intubation & Only $\mathrm{T}_{1}$ elicits response & $11.2 \pm 1.6$ & 0 \\
\hline At development of of maximal effect & No response & $1.5 \pm 0.4$ & 0 \\
\hline After discontinuation of infusion (min) & Responses elicited by & & \\
\hline $6.8 \pm 1.1$ & $T_{1}$ and $T_{2}$ & $15.3 \pm 1.2$ & 0 \\
\hline $12.1 \pm 1.2$ & $T_{1}, T_{2}$ and $T_{3}$ & $25.5 \pm 2.1$ & $0.04 \pm 0.01$ \\
\hline $15.6 \pm 1.3$ & $T_{1}, T_{2}, T_{3}$ and $T_{4}$ & $33.5 \pm 2.4$ & $0.10 \pm 0.01$ \\
\hline \multirow[t]{2}{*}{ After clinically satisfactory reversal } & Apparently equal responses to & & \\
\hline & $T_{1}, T_{2}, T_{3}$ and $T_{4}$ & $>90$ & $0.75 \pm 0.05$ \\
\hline
\end{tabular}

was considerable individual variation in the $\mu \mathrm{g} \cdot \mathrm{kg}^{-1} \cdot \mathrm{min}^{-1}$ vecuronium requirements. In this study the dose required varied from 0.38 to $1.5 \mu \mathrm{g} \cdot \mathrm{kg}^{-1}$. In another group of 16 similarly anaesthetized patients, monitored with MMG the dose of vecuronium was $1.03 \pm 0.07(0.55$ to 1.40$)$ $\mathrm{mg} \cdot \mathrm{kg}^{-1} \cdot \mathrm{min}^{-1}$ (Unpublished Nagashima $\mathrm{H}$ and Foldes FF). Recovery rate of NM transmission after the discontinuation of the infusion of vecuronium $(14.7 \pm 2.0 \mathrm{~min})$ was similar to that observed in patients in whom muscular relaxation was maintained by the injection of fractional doses (14.3 \pm 1.4$).{ }^{12}$ Recovery rates were independent of the duration of the infusion of vecuronium.

The observations summarized in Table III indicate that for clinical purposes completely satisfactory monitoring af the IV infusion of vecuronium can be achieved with the Myoscan. The trachea can be intubated when after the administration of the initial dose of vecuronium only $T_{1}$ elicits a response: the IV infusion of vecuronium should be started as soon as $T_{2}$ again elicits a response and its rate should be so regulated that only $T_{1}$ elicits a response for as long as relaxation is necessary. Residual NM block can be easily reversed, with moderate doses of anticholinesterases when $T_{4}$ also elicits a response: and reversal can be considered satisfactory when the responses to the TOF stimuli appear to be equal and similar to those observed before administration of the initial dose of vecuronium.

In conclusion, satisfactory muscular relaxation could be maintained with the continuous infusion of 0.38 to 1.50 $(0.90 \pm 0.05) \mu \mathrm{g} \cdot \mathrm{kg}^{-1} \cdot \mathrm{min}^{-1}$ vecuronium. Spontaneous recovery after discontinuation of the infusion was not influenced by the duration of infusion and was just as rapid as when vecuronium was administered in divided doses. ${ }^{12}$ If necessary residual NM block could be reversed by moderate doses of pyridostigmine. Because of the individual variation in the potency and duration of action of vecuronium NM block should be continuously monitored during the infusion of vecuronium. Satisfactory monitoring can be accomplished by a simple, inexpensive, easily applicable device, the Myoscan.

\section{References}

1 Agoston S, Salt P, Newton D, Bencini A, Boomsma $P$, Erdmann $W$. The neuromuscular blocking action of Org NC 45, a new pancuronium derivative, in anaesthetized patients. A pilot study. Br J Anaesth 1080; 52 : 53S-59S.

2 d'Hollander A, Massaux F. Nevelsteen M. Agoston S. Age-dependent dose-response relationship of Org NC 45 in anaesthetized patients. Br J Anaesth 1982: 54: 653-7.

3 d'Hollander AA, Czerurki $R$, Deville A, Cuvelier F. Stable muscle relaxation during abdominal surgery using combined intravenous bolus and demand infusion: clinical appraisal with Org NC 45. Can Anaesth Soc J 1982: 29: 136-41.

4 Noeldge G, Hinsken $H$, Buzella W. Comparison between the continuous infusion of vecuronium and the intermittent administration of pancuronium and vecuronium. $\mathrm{Br} \mathbf{J}$ Anaesth 1984: 56: 473-7.

5 Mirakhur RK, Ferres CJ, Pardit SK. Muscle relaxation with an infusion of vecuronium. Anesthesiology 1984: 61: A293.

6 d"Hollander A, Agaston S, Banais L, Massaut J, Baurain M. Evolution of vecuronium requirements for stable mechanical effect: comparison with or without previous succinylchaline administratin. Anesth Analg 1985: 64: 319-22

7 Swen J, Gencarelli PJ, Koot $H W J$. Vecuronium infusion dose requirements during fentanyl and halothane anesthesia in humans. Anesth Analg 1985: 64: 4I1-4.

8 ostergaard D, EngbaekJ, Ørding $H$, Morgensen $J$. Tactile evaluation of relaxation with atracurium and vecuronium administered in a continuous infusion. Acta Anaesthesiol Scand 1985: 29 suppl 80: 63. 
9 De Vries $J W$, Ros $H H$, Booij LHDJ. Infusion of vecuronium controlled by a closed-loop system. Br J Anaesth 1986: 58 : $1100-3$.

10 Cannon JE, Fahey MR, Castagnoli KP, Furua T, Sharma $M$, Miller $R D$. The effect of different anesthetics on a continuous vecuronium infusion. Anesth Analg 1986: 65: \$25.

11 Ali HH, Uting JE, Gray TC. Quantitative assessment of residual antidepolarizing block (part 1). Br J Anaesth 1973: 43: 473-85.

12 Duncall $D$, Nagashima H, Hollinger I, Badola RP, Kaplan $R$, Foldes $F F$. Relaxation with Org-NC45 during enflurane amesthesia. Anesthesiolngy 1981: 55: 203.

\section{Résumé}

On observe des variations individuelles considérables dans la dose de vécuronium requise pour le maintien du relâchement musculaire. Afin de fourmir un relachement ininterrompu sans surdosage il est à conseiller d'ajuster le débit de perfusion de vécuronium se basant sur une surveillance appropriée. La surveillance avec la mécanomyographie (MMG) ou l"electromyographie demande un equipement canteux et serait trop complare pour une utilisation ctinique de routine. La seule observation de la contraction du muscle adducteur du pouce contre aucune résistance n' est pas appropriée pour une évaluation fiable du degré du bloc neuromusculaire (NM). Pour des fins cliniques une surveillance satisfaisante peut être acquise avec un appareil simple (myoscan) qu' on décrit. La fiabilité du myoscan a été vérifiée chez 30 patients avec une surveitlance simulanée de la force de contraction clu mascle adductear du pouce avec le myoscan d' un cốté et du côté contralatéral cuvec le $M M G$. Une analvse rétrospective du MMG nous a indiqué que la conduite anesthésique aurait étê pratiquement la même si on s'était basé sur la surveillance du MMG. 